\title{
Pharmacokinetics and safety of bilastine in children aged 6 to 11 years with allergic rhinoconjunctivitis or chronic urticaria
}

\author{
Mónica Rodríguez ${ }^{1}$ • Valvanera Vozmediano ${ }^{1} \cdot$ Aintzane García-Bea $^{2} \cdot Z_{\text {Zoltán Novák }}^{3} \cdot$ Anahí Yáñez $^{4}$. \\ Cristina Campo ${ }^{2} \cdot$ Luis Labeaga $^{2}$
}

Received: 7 May 2019 / Revised: 25 November 2019 / Accepted: 23 December 2019 / Published online: 9 January 2020

(C) The Author(s) 2020

\begin{abstract}
Bilastine, a second-generation antihistamine, is approved in Europe for the treatment of allergic rhinoconjunctivitis and urticaria in adults and children aged $\geq 6$ years. Pharmacokinetic data for children aged 6-11 years were extracted post hoc from a study in which children (2-11 years) with allergic rhinoconjunctivitis or urticaria received oral bilastine (10 mg/day). Maximum plasma concentration $\left(C_{\max }\right)$ and area under the plasma concentration curve (AUC) data were compared with adult pharmacokinetic data from seven clinical studies (bilastine $20 \mathrm{mg}$ /day). Safety data for children aged 6-11 years were extracted post hoc from a phase III randomized controlled trial of children (2-11 years) with allergic rhinoconjunctivitis or chronic urticaria receiving once-daily bilastine $10 \mathrm{mg}$ or placebo for 12 weeks. Exposure and $C_{\max }$ values were similar for children (6-11 years) and adults: median pediatric/adult ratios for $\mathrm{AUC}_{0-24}$ and $C_{\max }$ were 0.93 and 0.91 , respectively. There was no significant difference in the incidence of treatment-emergent adverse in children (6-11 years) receiving bilastine $10 \mathrm{mg}$ or placebo.

Conclusion: Pharmacokinetic and safety analyses in children aged 6-11 years support the suitability of the pediatric dose of bilastine $10 \mathrm{mg}$ and confirm that the safety profiles of bilastine and placebo are similar.
\end{abstract}

What is Known:

- Bilastine, a second-generation antihistamine, is approved in Europe for the treatment of allergic rhinoconjunctivitis and urticaria in adults (20 mg/day) and children aged $\geq 6$ years $(10 \mathrm{mg} /$ day $)$.

- An ontogenic model based on adult data and pharmacokinetic/pharmacodynamic simulations supported the selection of a bilastine dose of $10 \mathrm{mg} /$ day in children aged 2-11 years. Bilastine $10 \mathrm{mg} /$ day was shown to have a safety profile similar to that of placebo in a large phase III randomized clinical trial in children aged 2-11 years.

What is New:

- As bilastine is approved in Europe for children aged $\geq 6$ years, the current study reports the results of two post hoc analyses of pharmacokinetic and safety data in children aged 6-11 years.

- Analysis of pharmacokinetic and safety data in children aged 6-11 years supports the suitability of the pediatric dose of bilastine 10 mg and confirms that its safety profile is similar to that of placebo.

Keywords Bilastine $\cdot$ Pharmacokinetics $\cdot$ Safety $\cdot$ Children $\cdot$ Allergic rhinoconjunctivitis $\cdot$ Urticaria

Communicated by Nicole Ritz

Aintzane García-Bea

agarciabea@faes.es

1 Drug Modeling \& Consulting, Dynakin S. L., Bilbao, Spain

2 Medical Department, FAES FARMA, S. A., 48940 Leioa, Bizkaia, Spain

3 Aranyklinika Egészségügyi és Innovációs Kft, Szeged, Hungary

4 INAER-Investigaciones en Alergia y Enfermedades Respiratorias, Buenos Aires, Argentina

\section{Abbreviations}

AUC Area under the plasma concentration curve

BMI Body mass index

$\mathrm{C}_{\max } \quad$ Maximum plasma concentration

CI Confidence interval

CV Coefficient of variation

ECG Electrocardiogram

NCA Non-compartmental analysis

PD Pharmacodynamic

PDCO Pediatric Committee of the European Medicines Agency

PK Pharmacokinetic 


$\begin{array}{ll}\text { PSQ } & \text { Pediatric Sleep Questionnaire } \\ \text { PT } & \text { Preferred term } \\ \text { SD } & \text { Standard deviation } \\ \text { SOC } & \text { System Organ Class } \\ \text { TAD } & \text { Time after dose } \\ \text { TEAE } & \text { Treatment-emergent adverse event }\end{array}$

\section{Introduction}

Bilastine is a second-generation non-sedating and non-brain penetrating antihistamine which is approved in Europe for the treatment of allergic rhinoconjunctivitis and urticaria in adults and children aged $\geq 6$ years with a body weight $\geq 20 \mathrm{~kg}$ [1-6]. Recently, bilastine has also been approved in Mexico for children aged $\geq 2$ years. The efficacy of bilastine is similar to that of other second-generation oral $\mathrm{H}_{1}$-antihistamines [7-9].

Pharmacokinetic (PK)/pharmacodynamic (PD) modeling in healthy adult subjects, complemented with noncompartmental analysis, demonstrated linear kinetics of orally administered bilastine over a dose range of 2.5 to $220 \mathrm{mg}$ [10]. In children aged 2 to 11 years, an ontogenic model based on adult data and PK/PD simulations supported the selection of a bilastine dose of $10 \mathrm{mg} /$ day [11], which was confirmed in a clinical PK study of children aged 4 to 11 years with allergic rhinoconjunctivitis or urticaria $[11,12]$.

As bilastine is approved in Europe for children aged 6 years or over, the current study reports the results of two post hoc analyses of PK and safety data. PK data generated by Vozmediano and colleagues [12] were analyzed, focusing on children aged 6-11 years. Secondly, a post hoc analysis of safety data in the same age group was conducted. These data were obtained from a phase III, placebo-controlled, randomized, controlled trial of bilastine $10 \mathrm{mg} /$ day for the treatment of children with allergic rhinoconjunctivitis or chronic urticaria [5].

\section{Methods}

\section{Pharmacokinetic data}

PK data were available from a multicenter, international, adaptive, open-label, repeated-administration study of oral bilastine $10 \mathrm{mg}$ /day in children aged 4 to 11 years with allergic rhinoconjunctivitis or urticaria (BILA-3009/PED study; ClinicalTrials.gov Identifier: NCT01081574). The study has been described in detail elsewhere [12].

Previous PK population modeling of children used subjects aged 4-11 years [11, 12]. This post hoc analysis focuses on children aged 6-11 years $(n=24)$, in line with the approved pediatric indication in Europe.

\section{Non-compartmental analysis}

The maximum plasma concentration $\left(C_{\max }\right)$ and area under the plasma concentration curve $\left(\mathrm{AUC}_{0-24}\right)$ were calculated using S-PLUS® (Version 8.2, TIBCO Software, Palo Alto, CA, USA).

\section{Comparison of NCA metrics in children with adults}

Systemic exposure following oral bilastine pediatric dose $(10 \mathrm{mg} /$ day $)$ was compared with adults (oral bilastine $20 \mathrm{mg} /$ day) using numerical and graphical comparisons, including the use of a forest plot to visually explore inter-study heterogeneity. For pediatric data, bilastine plasma concentration $(\mathrm{Cp})$ was plotted against time after dose (TAD) to account for sampling schedule differences.

Two alternative approaches were considered to establish reference $\mathrm{AUC}_{0-24}$ and $C_{\max }$ ranges in adults: the population-predicted $95 \%$ confidence interval (CI), based on the population PK model developed with adult data [10], and the more conservative $95 \% \mathrm{CI}$, based on NCA values obtained from seven Phase I studies (studies 459-02, 459-04 to 459-07, 459-10, and 459-11) in adults following bilastine $20 \mathrm{mg}$ dosing.

\section{Safety data}

Safety data were extracted from a phase III, double-blind, randomized, placebo-controlled, parallel-group study of children aged 2-11 years with allergic rhinoconjunctivitis or chronic urticaria treated once-daily with bilastine $10 \mathrm{mg}$ $(n=260)$ or placebo $(n=249)$ for 12 weeks [5]. Full study details and results have been published previously [5].

Bilastine $(10 \mathrm{mg})$ or placebo was administered orally once daily in the morning under fasting conditions for 12 weeks. Occasional use of rescue medication - short-term topical decongestants (eye/nose), corticosteroids or antihistamines for rhinoconjunctivitis, or short-term topical corticosteroids for urticaria was permitted.

The primary outcome was the proportion of children in each treatment group without any treatment-emergent adverse events (TEAEs; defined as any type of adverse events which occurred during the entire 4-month study duration (i.e., 3month treatment period and 1-month follow-up period)), in accordance with PDCO guidance.

\section{Statistical analysis}

Statistical significance was assessed for two-sided tests with an alpha of 0.05 as the cutoff for significance. Missing values were not considered for statistical calculations. Quantitative variables were described by the number of subjects, mean, standard deviation (SD), maximum, minimum, and quartile 
values. Qualitative variables were described by frequency and percentage. Secondary categorical variables were assessed using the chi-squared test or Fisher's exact test if applicability conditions were not met.

\section{Results}

\section{Pharmacokinetic data}

A total of 88 samples from 24 children aged 6 to 11 years were collected, which enabled characterization of the absorption, distribution, and elimination phases of the PK profile in this cohort. Exposures and maximum plasma concentrations in the pediatric population ( $n=12$, corresponding to children with a rich PK profile in this sparse sampling design) after dosing with bilastine $10 \mathrm{mg}$ /day were similar to those reported for adult PK data $(n=126)$ obtained from 7 clinical studies following daily dosing with bilastine $20 \mathrm{mg}$ (Table 1). Median (SD) $\mathrm{AUC}_{0-24}$ in the pediatric and adult populations was 1045 (381) and 1121 (387) $\mathrm{ng} \cdot \mathrm{h} / \mathrm{mL}$, respectively, and median $C_{\max }$ was 212.0 (123) and 232.5 (120) $\mathrm{ng} / \mathrm{mL}$, respectively. Bilastine plasma concentrations observed in children completely overlapped those in adults, falling well within the adult variability, and followed the same PK temporal shape. Median pediatric/adult ratios for $\mathrm{AUC}_{0-24}$ and $C_{\max }$ were 0.93 and 0.91 , respectively. Moreover, systemic exposure and $C_{\max }$ following oral bilastine pediatric dose $(10 \mathrm{mg} /$ day) was compared with adults (oral bilastine $20 \mathrm{mg} /$ day) with the use of a forest plot (Fig. 1) showing that the pediatric PK metrics are completely inside the adult confidence intervals.

\section{Safety data}

The safety population comprised 393 subjects who received study medication and was randomized to receive bilastine $10 \mathrm{mg}(n=202)$ or placebo $(n=191)$. The mean (SD) age of the bilastine and placebo groups was 8.5 (1.6) and 8.5 (1.8) years, respectively. In the bilastine group, 105 (52\%) subjects were aged 6-8 years, and $97(48 \%)$ aged 9-11 years. Respective numbers in the placebo group were 95 (49.7\%) and $96(50.3 \%)$. Subjects in the bilastine and placebo groups were mainly male $(62.9 \%$ and $61.8 \%$, respectively) and Caucasian (93.1\% and 92.7\%). Mean (SD) body mass index (BMI) in the two groups was 18.0 (3.5) and $18.1(3.5) \mathrm{kg} / \mathrm{m}^{2}$, respectively. Subjects were diagnosed with allergic rhinoconjunctivitis $(98.0 \%$ and $93.7 \%$ ) or chronic urticaria $(2.0 \%$ and $6.3 \%)$, with a mean (SD) time since diagnosis of 4.1 (2.5) and $4.0(2.7)$ years, respectively.

There was no significant difference in the incidence of TEAEs between the two groups: 137 events were reported in $67.8 \%$ of children receiving bilastine compared with 129 events in $67.5 \%$ receiving placebo $(p=0.952)$. Rates of children with related-TEAEs in the bilastine and placebo groups were $5.4 \%$ and $7.9 \%$, respectively $(p=0.337)$; rates of children with serious TEAEs were $1.0 \%$ and $3.1 \%$, respectively $(p=0.165)$, although none were considered to be treatment related; and rates of children with TEAEs leading to discontinuation were $1.0 \%$ and $0.5 \%$, respectively $(p=1.0)$.

The most frequent TEAEs ( $\geq 5 \%$ frequency) in the bilastine and placebo groups were headache (13.4\% vs. $12.6 \%)$, allergic conjunctivitis $(9.9 \%$ vs. $9.4 \%)$, cough $(8.9 \%$ vs. $7.9 \%)$, nasopharyngitis $(7.9 \%$ vs. $4.7 \%)$, pharyngitis $(7.4 \%$ vs. $6.8 \%)$, allergic rhinitis $(6.4 \%$ vs. $10.0 \%)$, pyrexia (5.0\% vs. $10.0 \%$ ), and viral infection ( $4.5 \%$ vs. $5.2 \%)$, respectively.

\section{Discussion}

Results from the post hoc PK study of bilastine in children aged 6-11 years with allergic rhinoconjunctivitis or urticaria align with those from a larger pediatric population (aged 211 years) which indicated a lack of age dependence for bilastine PK $[11,12]$. The current PK analysis was limited to children aged 6-11 years, which is in line with the approved pediatric indication for bilastine in Europe: $\geq 6$ years of age with a body weight of $\geq 20 \mathrm{~kg}$. Pediatric data in the full dataset (aged 4-11 years) were best described by a two-compartment

Table 1 Summary statistics for bilastine pharmacokinetic parameters $\mathrm{AUC}_{0-24}$ and $C_{\text {max }}$ calculated in adults (bilastine $20 \mathrm{mg}$ once daily) in seven clinical studies and in children aged 6-11 years (bilastine $10 \mathrm{mg}$

once daily) from the PK study (BILA-3009/PED). Only children who had a complete PK profile were included $(n=12)$

\begin{tabular}{|c|c|c|c|c|c|c|c|c|}
\hline Parameter & Study & $N$ & Mean & Median & $\mathrm{SD}$ & $\mathrm{CV}(\%)$ & $\begin{array}{l}\text { Range } \\
(\min -\max )\end{array}$ & $95 \% \mathrm{CI}$ \\
\hline \multirow[t]{2}{*}{$\mathrm{AUC}_{0-24}(\mathrm{ng} \cdot \mathrm{h} / \mathrm{mL})$} & Adults (studies $459-02,459-04$ to $459-07,459-10,459-11$ ) & 126 & 1160 & 1121 & 387 & 33.4 & $491-2528$ & $1092-1227$ \\
\hline & Children aged 6-11 years (study: BILA-3009/PED) & 12 & 1014 & 1045 & 381 & 37.6 & $363 *-1653$ & $798-1230$ \\
\hline \multirow[t]{2}{*}{$C_{\max }(\mathrm{ng} / \mathrm{mL})$} & Adults (studies $459-02,459-04$ to $459-07,459-10,459-11$ ) & 126 & 259.8 & 232.5 & 120 & 46.2 & $83-924$ & $239-281$ \\
\hline & Children aged 6-11 years (study: BILA-3009/PED) & 12 & 239.2 & 212.0 & 123 & 51.5 & $61-447$ & $170-309$ \\
\hline
\end{tabular}

*Minimum AUC value, identified in a single child and classed as a statistical outlier

95\% CI, 95\% confidence interval; $C V$, coefficient of variation; $S D$, standard deviation 


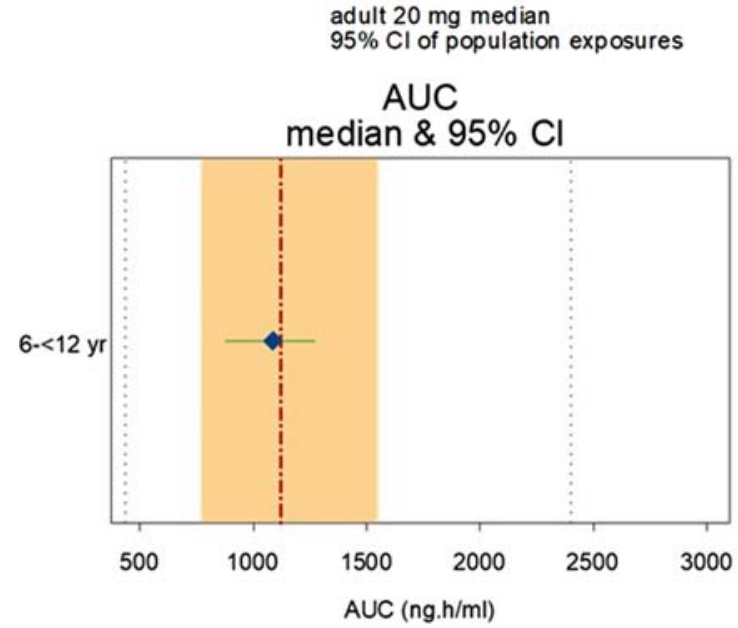

Fig. 1 Forest plot for bilastine exposure (AUC) and $C_{\max }$ from observations in children (6-11 years old) in study BILA-3009/PED after the $10 \mathrm{mg}$ dose and adults after $20 \mathrm{mg}$ dose in several clinical studies (studies 459-02, 459-04 to 459-07, 459-10, 459-11). Blue dots represent the median values, and the green lines are the $95 \%$ confidence interval (95\% CI) observed in children. The red line and the orange shaded area are the

disposition model [11, 12], which is the same used to describe bilastine PK in adults [10]. Both $\mathrm{AUC}_{0-24}$ and $C_{\max }$ metrics between children (aged 6-11 years) and adult groups were very similar, with a complete overlap of pediatric bilastine plasma concentrations with those of adults, and pediatric/ adult ratios for $\mathrm{AUC}_{0-24}$ and $C_{\max }$ were close to unity (0.93 and 0.91 , respectively). These results support the suitability of the pediatric dose of bilastine $10 \mathrm{mg}$.

Safety data were derived from analysis of a subset of data (in children aged 6-11 years) from the phase III, placebocontrolled randomized trial of bilastine in children aged 2 to 11 years with allergic rhinoconjunctivitis or chronic urticaria [5]. In this post hoc analysis, there was no significant difference in the incidence of TEAEs in children receiving bilastine $(10 \mathrm{mg})$ or placebo, with headache being the most commonly reported adverse effect in both groups (13.4\% vs. $12.6 \%$, respectively). These results confirm that, in children, bilastine $10 \mathrm{mg}$ has a safety and tolerability profile similar to that of placebo [5]. In adults, bilastine at the recommended dose of $20 \mathrm{mg}$ has an excellent safety profile, with good tolerability and no sedative effects or cardiotoxicity [2, 7-9].

In conclusion, analysis of $\mathrm{PK}$ and safety data in children aged 6-11 years supports the suitability of the pediatric dose of bilastine $10 \mathrm{mg}$ and confirms that its safety profile is similar to that of placebo.

Acknowledgments Under the direction of the authors, editorial assistance was provided by Robert A. Furlong $\mathrm{PhD}$ and David P. Figgitt PhD, ISMPP CMPPTM, Content Ed Net, with funding from FAES FARMA S.A., Spain.

Authors' contributions All authors contributed extensively to the work presented in this paper. All authors have contributed significantly to the

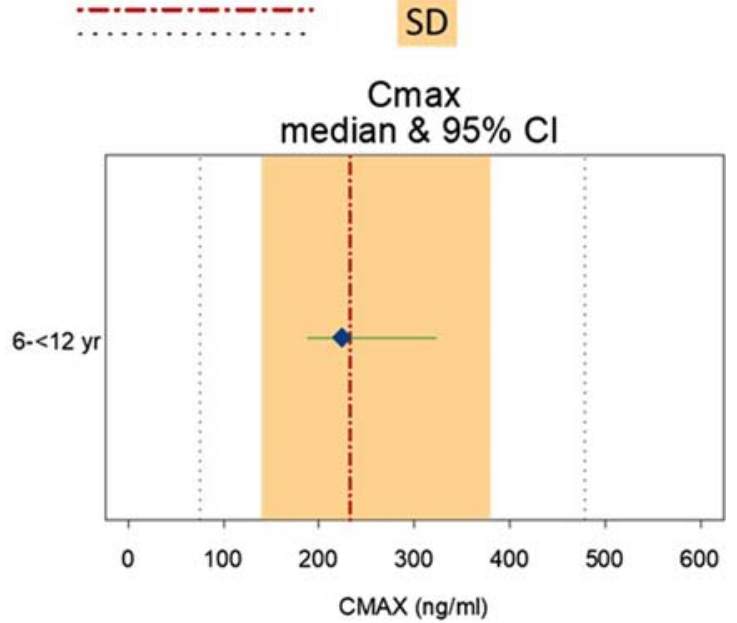

median value, and one standard deviation in the adult global population, respectively. In addition, the $95 \%$ CI of population exposures, as predicted by the population PK/PD model in adults after a $20 \mathrm{mg}$ dose (435$2400 \mathrm{ng} \mathrm{h} / \mathrm{mL}$ (AUC) and $75-475 \mathrm{ng} / \mathrm{mL}\left(C_{\max }\right)$ ), are represented by the black dotted lines

conception, design, or acquisition of data, or analysis and interpretation of data; drafting/revising the manuscript for important intellectual content; and approval of the final version to be published.

Funding information The study was financially supported by FAES FARMA, S. A.

\section{Compliance with ethical statements}

Conflict of interest CC, AGB, and LL are full-time employees of FAES FARMA S. A. MR and VV have no conflicts of interest other than receiving funding from FAES FARMA, S.A., for designing the PK trial and conducting the modeling and simulation analysis. The remaining authors have no relevant affiliations or financial involvement with any organization or entity with a financial interest in or financial conflict with the subject matter or materials discussed in the manuscript apart from those disclosed.

Ethical approval The study was approved by the Pediatric Committee of the European Medicines Agency (PDCO) and conducted in accordance with the principles of the Declaration of Helsinki. The study was conducted at eight sites in four countries (Australia, Germany, Spain, and Sweden), all of which had received previous approval by the corresponding Institutional Review Board.

Informed consent Parents provided written consent and children, when considered to be old enough, provided assent for participation.

Open Access This article is licensed under a Creative Commons Attribution 4.0 International License, which permits use, sharing, adaptation, distribution and reproduction in any medium or format, as long as you give appropriate credit to the original author(s) and the source, provide a link to the Creative Commons licence, and indicate if changes were made. The images or other third party material in this article are included in the article's Creative Commons licence, unless indicated otherwise in a credit line to the material. If material is not included in the article's Creative Commons licence and your intended use is not permitted by statutory regulation or exceeds the permitted use, you will need to obtain 
permission directly from the copyright holder. To view a copy of this licence, visit http://creativecommons.org/licenses/by/4.0/.

\section{References}

1. Bachert C, Kuna P, Zuberbier T (2010) Bilastine in allergic rhinoconjunctivitis and urticaria. Allergy 65:1-13

2. Church MK (2011) Safety and efficacy of bilastine: a new H(1)antihistamine for the treatment of allergic rhinoconjunctivitis and urticaria. Expert Opin Drug Saf 10:779-793

3. Church MK, Labeaga L (2017) Bilastine: a new H1 -antihistamine with an optimal profile for updosing in urticaria. J Eur Acad Dermatol Venereol 31:1447-1452

4. Kawauchi H, Yanai K, Wang DY, Itahashi K, Okubo K (2019) Antihistamines for allergic rhinitis treatment from the viewpoint of nonsedative properties. Int J Mol Sci 20:E213

5. Novák Z, Yáñez A, Kiss I, Kuna P, Tortajada-Girbés M, Valiente R; "Bilastine Paediatric Safety Study Group" (2016) Safety and tolerability of bilastine $10 \mathrm{mg}$ administered for 12 weeks in children with allergic diseases. Pediatr Allergy Immunol 27:493-498

6. Medicines and Healthcare products Regulatory Agency (MHRA). Summary of product characteristics. Ilaxten $10 \mathrm{mg}$ orodispersible tablets, bilastine. 2018; Available from: http://www.mhra.gov.uk/ home/groups/spcpil/documents/spcpil/con1555647558167.pdf (accessed 30 April 2019)
7. Sádaba B, Azanza JR, Gomez-Guiu A, Rodil R (2013) Critical appraisal of bilastine for the treatment of allergic rhinoconjunctivitis and urticaria. Ther Clin Risk Manag 9:197-205

8. Ridolo E, Montagni M, Bonzano L, Incorvaia C, Canonica GW (2015) Bilastine: new insight into antihistamine treatment. Clin Mol Allergy 13:1

9. Wang XY, Lim-Jurado M, Prepageran N, Tantilipikorn P, de Wang Y (2016) Treatment of allergic rhinitis and urticaria: a review of the newest antihistamine drug bilastine. Ther Clin Risk Manag 12:585597

10. Jauregizar N, De la Fuente L, Lucero ML, Sologuren A, Leal N, Rodríguez M (2009) Pharmacokinetic-pharmacodynamic modelling of the antihistaminic (H1) effect of bilastine. Clin Pharmacokinet 48:543-554

11. Vozmediano V, Sologuren A, Lukas JC, Leal N, Rodriguez M (2017) Model informed pediatric development applied to bilastine: ontogenic PK model development, dose selection for first time in children and PK study design. Pharm Res 34:2720-2734

12. Vozmediano V, Lukas JC, Encinas E, Schmidt S, Sologuren A, Valiente R, Labeaga L, Campo C, Rodriguez M (2019) Modelinformed pediatric development applied to bilastine: analysis of the clinical PK data and confirmation of the dose selected for the target population. Eur J Pharm Sci 128:180-192

Publisher's note Springer Nature remains neutral with regard to jurisdictional claims in published maps and institutional affiliations. 